\title{
JORNAL COMO PROPOSTA DE EDUCAÇÃO PARA A CIDADANIA
}

\begin{abstract}
Alunos desenvolvem jornal em sala de aula e aprendem a estabelecer relações entre o cotidiano e a prática escolar
\end{abstract}

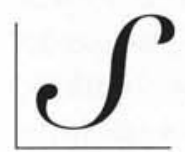

empre tive a intenção de fazer com que meus alunos elaborassem um jornal, contendo experiências acontecidas no decorrer do bimestre (passeios, datas comemorativas etc.), mas nunca havia pensado em trabalhar com notícias de jornal e reportagens. A experiência que vou relatar, realizada com alunos de primeira a quarta séries do ensino fundamental, foi muito gratificante porque superou minhas próprias expectativas como educadora e despertou, nos alunos, o interesse pela notícia e pelo que ocorre no seu cotidiano. $\mathrm{O}$ principal objetivo do trabalho era fazer com que eles se vissem como parte inte- grante da sociedade, com capacidade de nela intervir e modificá-la.

Tudo começou quando decidi trabalhar com textos informativos da revista Ciência Hojel com o intuito de desenvolver nos alunos a consciência de que o meio ambiente é também o lugar onde eles vivem o seu cotidiano e não trata apenas da água, da floresta, dos rios. Os primeiros textos trabalhados foram sobre o lixo, o buraco na camada de ozônio, os perigos do Sol e o efeito estufa.

Certo dia, os próprios alunos chegaram comentando sobre clonagem, assunto sobre o qual tinham ouvido falar no programa Sai de Baixo, da Rede Globo. Aproveitei e utili- 
zei a revista Ciência Hoje para ler junto com eles sobre a primeira clonagem - a da ovelha Dolly. Fizemos uma síntese do assunto. Depois, pedi que trouxessem recortes de jornais e revistas que falassem de clonagem. Eles trouxeram muitas notícias e assim pudemos montar um mural, constando as datas e os nomes dos jornais e das revistas de onde foram retiradas as reportagens.

Enquanto pesquisavam nos jornais, algumas crianças ficaram chocadas com as notícias publicadas e as trouxeram para a classe. Eram notícias do dia-a-dia, às vezes chocantes, como por exemplo: "mãe corta a língua de bebê"; "pai põe fogo na casa e mata seus quatro filhos"; "a morte de Tim Maia”. Também despertaram interesse notícias sobre a Copa do Mundo. Então, resolvemos fazer um mural à parte com estes outros temas. Estava se delineando uma proposta nova de trabalho em sala de aula.

Passamos, assim, a desenvolver um trabalho em grupo. As crianças ficaram entusiasmadas e cada vez traziam mais recortes. Cada notícia era lida em sala de aula e depois era produzido um texto coletivo, dando seqüência aos fatos tirados do jornal.

Durante todo o bimestre, seguimos com essa atividade. Líamos os recortes, conversávamos sobre as notícias, eu fazia perguntas sobre os textos, e, ao final, elaborávamos a síntese das notícias. Percebi que havia conseguido total integração da sala de aula. Todos participavam e as discussões estavam ampliando o universo dos alunos. Eles se sentiam capazes e, bem informados, podiam se posicionar diante dos assuntos.

Em função do sucesso da atividade, surgiu a idéia de aproveitar os assuntos trazidos para elaborar com eles o jornal da classe. A idéia original, de buscar informações na revista Ciência Hoje para complementar a aula, ampliou-se. O projeto do jornal começou a ganhar forma e as atividades foram desenvolvidas em duas etapas: dois meses para a coleta de material (notícias, reportagens etc.) e um mês para a confecção do jornal.

\section{PRODUÇÃO DO JORNAL}

O processo de produção do jornal foi bastante artesanal. O que, de certa forma, enriqueceu ainda mais a proposta, já que as crianças tiveram de se desdobrar para alcançar um bom resultado. Tudo dependia muito do interesse e da disposição deles.

Os temas foram colocados na lousa e cada aluno escolheu o assunto sobre o qual queria escrever. A empolgação tomou conta de todos e logo a produção estava pron-

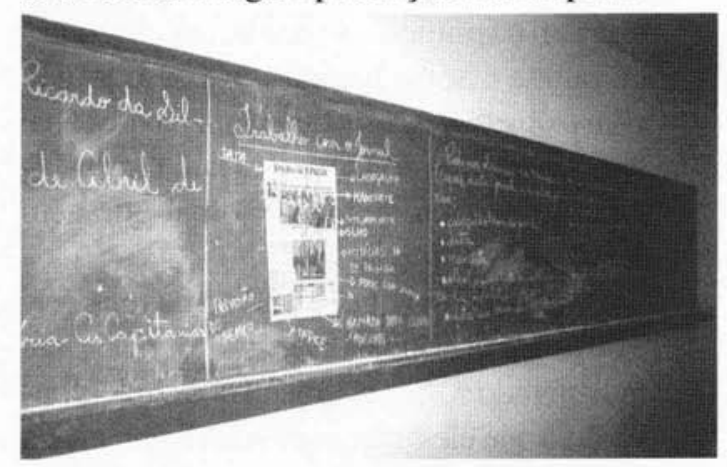

$\Delta$ O trabalho com o jornal inicia-se com o detalhamento de cada um de seus componentes.

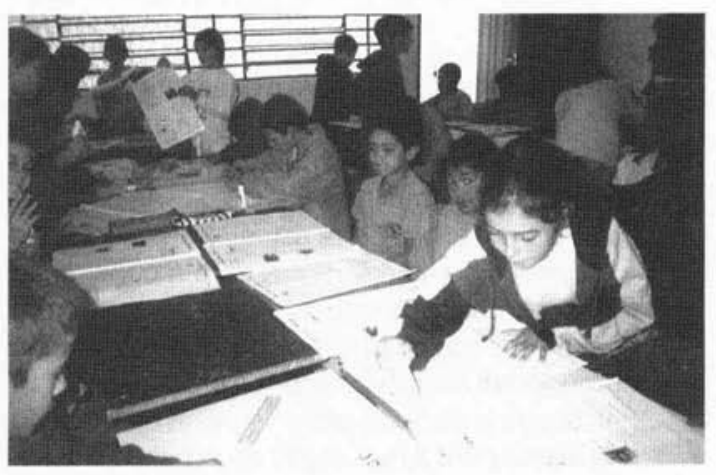

A Os alunos trabalham em grupo e escrevem textos, títulos, recortam e colam imagens, produzindo animadamente o jornal da classe. 
ta. Corrigi os textos, apenas os erros mais graves de escrita, sem mudar a maneira como foram redigidos.

Pedi para que escrevessem os textos a lápis em letra de forma, num sulfite, onde teriam de medir para fazer margem e linhas para escrever. Depois de pronto, cobriram com caneta, apagaram as linhas e entregaram. Tiramos xerox, reduzindo a $50 \%$ do seu tamanho, em seguida montamos o jornal. $\mathrm{O}$ nome, Jornal Legal, foi decidido em eleição.

A partir daí, entramos no trabalho de composição da capa. Fizemos um estudo sobre o que encontramos nas primeiras páginas dos jornais (manchete, olho, índice, gráficos, previsão do tempo, chamadas para outras notícias, nome do jornal, data, edição etc.). $\mathrm{Na}$ lousa, discriminamos os assuntos que estavam na primeira, segunda, terceira, quarta, quinta e sexta páginas do nosso jornal, com o objetivo de fazer as chamadas de capa. Nesta altura, as crianças estavam tão envolvidas com a produção do jornal que nem sentiam o tempo passar.

Pude perceber que, usando o método certo, é possível ensinar divertindo. E mais, que trabalhando com o cotidiano dos alunos, ouvindo o que eles trazem de sua vivência, fica mais fácil mobilizá-los para o aprendizado.

Bem, ainda precisávamos de uma bela

Resumo: O artigo descreve a experiência de uma professora da rede municipal de ensino de Santos, São Paulo, através da qual foi possível desenvolver um jornal na sala de aula. As noticias, colhidas em jornais e revistas, eram discutidas e utilizadas como referência para a construção de textos coletivos que iam para murais. Além dessa fase de discussão, na qual os alunos aprenderam um pouco sobre a produção do jornal, houve a parte de pesquisa e de elaboração dos textos para a realização do jornal da classe.

Palavras-chave: jornal, ensino, cotidiano, jornal na escola capa. Resolvemos fazer um concurso, do qual saíram cinco ganhadores, levando-nos a realizar um segundo turno. A competição acirrada foi mais um ingrediente de empolgação e de expectativa. Finalmente, escolhemos a capa e terminamos o jornal. Cada aluno ficou com um exemplar e fez a montagem, colocando as páginas.

Foi muito gratificante ver o entusiasmo e a alegria das crianças. Elas se sentiram importantes com a produção e a consideraram tão boa que sugeriram a sua venda.

Aquilo que, em princípio, tinha sido uma proposta de complemento de atividade em sala de aula, acabou se transformando em uma alternativa eficaz de ensino. Uma opção que privilegia a criatividade do aluno, sua participação efetiva, além de estar em sintonia com a proposta de educação com, pelo e para os meios de comunicação.

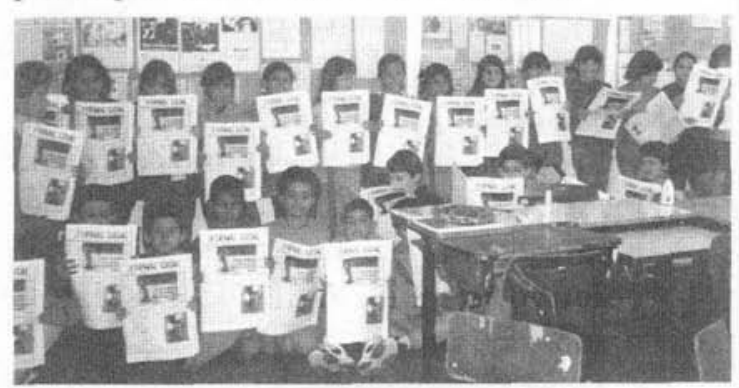

Toda classe trabalhou para elaborar o Jornal Legal.

Abstract. The article describes the experience of a Santos, São Paulo, municipal school-teacher, through which it was possible to put together a newspaper in the classroom. The news, gathered from newspapers and magazines, was discussed and used as reference to elaborate collective texts that would then be placed on murals. Over and beyond this discussion phase, in which the students learnt a little bit about newspaper production, there was the research and newspaper text elaboration part for the class paper.

Key words: newspaper, teaching, day-to-day life, newspaper at school 